\title{
Methylmercury in suspended particles of a peri-alpine deep lake
}

\author{
ANDREA GALLORINI AND JEAN-LUC LOIZEAU
}

University of Geneva

Presenting Author: andrea.gallorini@unige.ch

Among mercury species, the most toxic for human and wildlife is methylmercury $(\mathrm{MeHg})$, a liposoluble neurotoxin that biomagnifies along the food chain. $\mathrm{MeHg}$ is produced mainly in aquatic systems by microbial activity taking place in anoxic compartments. Bottom sediments of marine and freshwater environments are well-known as privileged production sites of MeHg. Nevertheless, growing evidence shows that a nonnegligible fraction of $\mathrm{MeHg}$ is produced within the water column associated with hypoxic layers and high particulate organic carbon (POC) concentrations. Following this evidence, we investigate the presence of $\mathrm{MeHg}$ in suspended particles in Lake Geneva (Switzerland, France). We developed a specific setup to collect and analyse samples as close as possible to their natural conditions avoiding any external interference. We collected suspended particles from the lake using continuous flow filtration on large diameter glass-fiber filters, and suspended particles from the main tributaries using continuous flow centrifugation, to estimate the fraction of the total $\mathrm{MeHg}$ present in the lake coming from the catchment area. Sampling depths were selected based on DO concentrations, determined using a "Seabird" multiprobe to record vertical profiles of ancillary parameters (temperature, $\mathrm{pH}, \mathrm{DO}$, turbidity, conductivity, fluorescence). Results are shown as ranges of $\mathrm{MeHg}$ concentrations in suspended particles at the different depths following the DO peaks displacement throughout the year. $\mathrm{MeHg}$ concentrations range from $2.53 \pm 0.62$ to $8.35 \pm 0.20 \mathrm{ng} / \mathrm{g}$ at $15 \mathrm{~m}$ depth (at positive oxygen peak); from $1.70 \pm 0.39$ to $3.84 \pm 0.28$ $\mathrm{ng} / \mathrm{g}$ between 25 and $30 \mathrm{~m}$ depth (at negative oxygen peak) and from $3.98 \pm 0.21$ to $9.61 \pm 0.67 \mathrm{ng} / \mathrm{g}$ at $100 \mathrm{~m}$ depth. These $\mathrm{MeHg}$ are significantly higher than concentrations measured on suspended particles from the two main tributaries (Rhone River: from $0.12 \pm 0.02$ to $0.61 \pm 0.04 \mathrm{ng} / \mathrm{g}$; Dranse River: from $0.30 \pm 0.08$ to $1.77 \pm 0.09 \mathrm{ng} / \mathrm{g}$ ), and also higher than those reported from bottom sediment, with $\mathrm{MeHg}$ contents ranging from $0.31 \pm 0.03$ to $1.67 \pm 0.02 \mathrm{ng} / \mathrm{g}$. These results strongly suggest an in situ production of $\mathrm{MeHg}$ in the lake water column and overall a nonnegligible role of the suspended particles as $\mathrm{MeHg}$ production microenvironments. 